\title{
Refinement and Screening Geographical Elements and Characteristics of Natural Landscape in Panjin Region
}

\author{
Wang Jinxia, Yan Hongwei, Wang Ningwen \\ College of Horticulture, Shenyang Agricultural University, Shenyang, China \\ Email address: \\ wangjinxia74@163.com (Wang Jinxia),yhwww@sina.com (Yan Hongwei),wnwde163@163.com (Wang Ningwen) \\ To cite this article: \\ Wang Jinxia, Yan Hongwei, Wang Ningwen. Refinement and Screening Geographical Elements and Characteristics of Natural Landscape in \\ Panjin Region. Humanities and Social Sciences. Vol. 6, No. 2, 2018, pp. 82-87. doi: 10.11648/j.hss.20180602.16
}

Received: April 17, 2018; Accepted: June 14, 2018; Published: June 26, 2018

\begin{abstract}
Natural landscape refers to the natural complex formed by the interaction of natural elements. It is the basis for the formation of man-made landscapes. This paper uses Google maps and on-site investigations to investigate the natural landscape in Panjin City and investigate its natural landscape elements such as landforms, vegetation, soil, water bodies, and animals. According to the regional landscape connotation, the assessment criteria for regional landscape elements are determined to screen out regional features. The natural landscape constituent elements refine the characteristics of regional natural landscape elements, providing a theoretical basis and practical guidance for the landscape construction of a region. The result is that the elements of geographical landscape are screened out: vegetation is the dominant factor; landforms and soil are the basic elements; water is the influence factor; birds and river crabs are the ecological elements. Characteristics of regional components in Panjin region are by a wide and flat terrain, vertical and horizontal rivers, and tidal creeks. The plants are relatively single, there are few woody plants, and there are many salt-tolerant wet plants. Large areas of 'Red Beach', vast reed marshes, reed meadows, and red and green dynamic zonal shoal landscapes have a distinct color season. It creates a diverse ecological environment for birds and crabs. Large-scale groups have also become the most symbolic geographical symbol in Panjin region.
\end{abstract}

Keywords: Geographical Elements, Natural Landscape, Phragmites australis, Suaeda salsa

\section{Introduction}

Natural landscape refers to the natural complex formed by the interaction of natural constituent elements and is the basis for the formation of regional landscapes. [1-2] Regional landscapes can reflect the distinctive features of an area. [3-4] The regions are determined by their physical geographical factors. [5] Landscape composition varies by species, number, and distribution area. [6] It is a world-famous wetland tourism city for Panjin. The existing research focuses mainly on the ecological research of wetlands. while the study on the regional landscape is still in a deficient situation. [7-9] For this purpose, the subject of research is in the Panjin area, and the constituent elements of the natural landscape are investigated. According to connotation of the regional landscape, the evaluation criteria for the regional landscape elements are formulated, the regional natural landscape elements are selected, and the characteristics of the regional natural landscape elements are extracted. Provide theoretical basis and practical guidance for landscape construction in a region.

Panjin is politically an administrative unit, but this area is a widely used geographical concept for the downstream of the Liaohe River region. Local residents also have a strong sense of belonging and identity with Panjin region. In order to facilitate statistical data, the survey data in Panjin city area shall prevail in Panjin region. Natural landscapes are defined as purely natural landscapes and semi-natural landscapes that are less affected by humans.

\section{Research Area and Methods}

It is located in the southwest of Liaoning Province and the center of the Liao River Delta in Panjin between latitude $40^{\circ} 40^{\prime} \sim 41^{\circ} 27^{\prime} \mathrm{N}$, longitude $121^{\circ} 31^{\prime} \sim 122^{\circ} 28^{\prime} \mathrm{E}$, and the east boundary Liao river is connected with Anshan City, the south of the great Liao river and Yingkou City, northwest border with Jinzhou City, southwest coast Bohai Sea. The north and 
south end of the border are $87 \mathrm{~km}$ long, $105 \mathrm{~km}$ wide, and 4 $071 \mathrm{~km}^{2}$, with a total population of 1.3 million. This area belongs to warm temperate continental semi-humid monsoon climate with intense seasonal changes. There are two flood seasons in spring and summer each year. The average annual temperature is $8.3^{\circ} \mathrm{C} \sim 8.4^{\circ} \mathrm{C}$, and the rainy season is mainly concentrated in summer. Panjin is low-lying and flat, with an elevation of 2 to $4 \mathrm{~m}$, in the territory of many water and no mountain. The mother rivers in Panjin-Liao River (Shuangtaizi River) and the Da Liao River, Da Ling River and other 21 large and small rivers hover in the territory. The northwest can glimpse the majestic Mount Lv, and the southwest can expect the vast sea of Bohai. Its warm temperate and semi-humid monsoon climate, rich water resources and the Liao River Delta region provide abundant wetland resources in this area, providing good conditions for the growth of vegetation here, and providing excellent habitat for birds, fish and crabs.

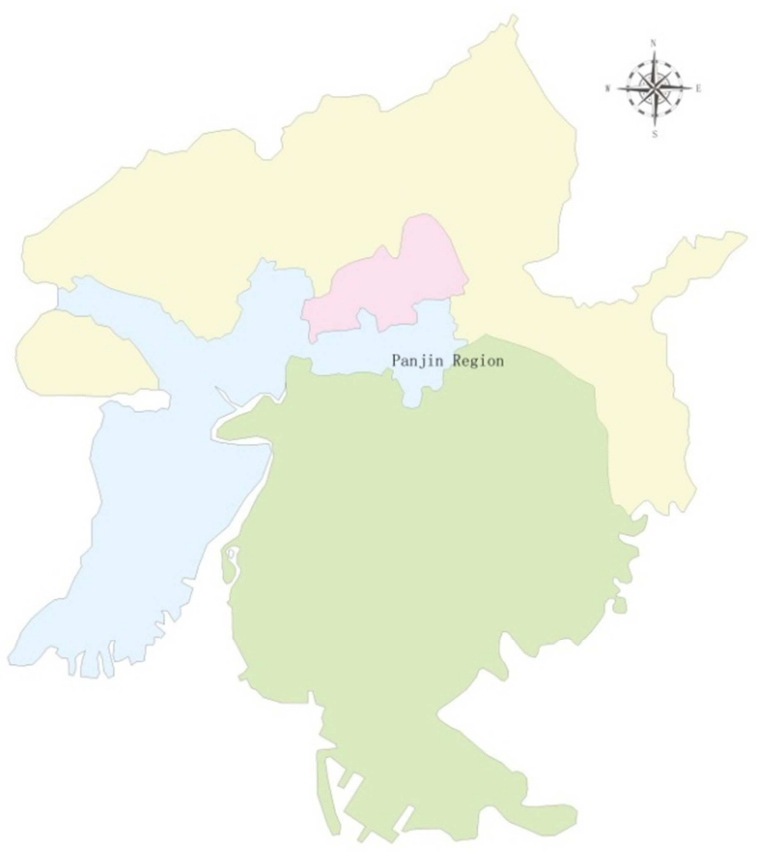

Figure 1. Administrative region in Panjin region.

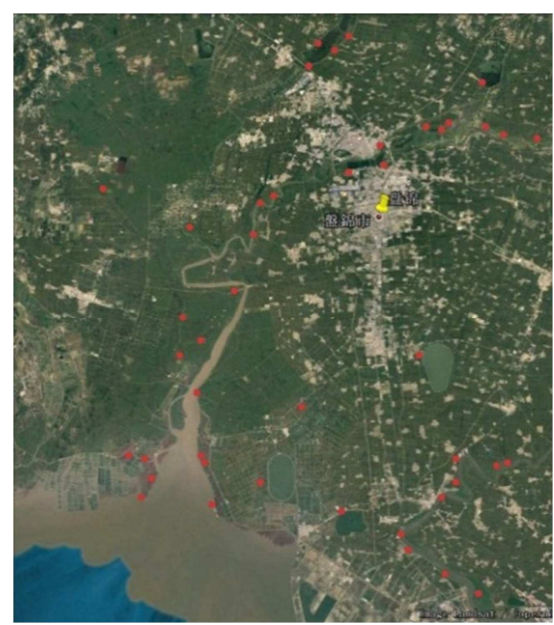

Figure 2. Survey location.
In the area of Panjin, the Google map was used to initially select the survey site, and then 45 sites were selected for investigation, including mainly the Liaohe estuary, river bank, Daliao River estuary, bank, river bank, Zhaoquanhe reed field, and Yangjuanzi reed field. In these places, methods for surveying landforms, vegetation, soil, water bodies, animals and landscapes draw on ecological methods in the 2014-2015 year.[10]

\section{Research Results and Analysis}

\subsection{Composition Elements of Natural Landscape}

\subsubsection{Climate}

It is the north temperate zone in Panjin region, with warm and humid air, monsoon climate, and windy winds throughout the year. The climate here is characterized by ample sunshine and four distinct seasons. In spring, the wind is strong, there is little rain, and the climate is dry; in summer, the hottest month is July; in autumn, the weather is fine, the temperature drops sharply and cool; the average temperature in winter is $22^{\circ} \mathrm{C} \sim 24^{\circ} \mathrm{C}$, the coldest month in January, it is cold with an average temperature of $-9 \sim-11^{\circ} \mathrm{C}$.

Climate and plant distribution, flowering seasons, seasonal changes, move of migratory birds, and human living habits are closely linked.

\subsubsection{Topography and Landforms}

Landforms are relatively stable landscape elements formed by the interaction of internal and external forces in the earth's crust. Landforms affect other elements in the landscape. For the Panjin region, the landscape is the basic component of the natural landscape and the most important external feature of the natural landscape. In addition to places such as northeast is high terrain slightly higher about $10 \mathrm{~m}$ in Panjin, the terrain from north to south gradually decrease. The main landform is the alluvial plain of the retreat in Panjin region. There are many rivers, no mountains and less trees. There are numerous plains, rivers, floodplains, depressions, and mud flats. Beaches are mainly distributed in Dawa County, Rongxing, Erjiegou, Yushu, Wangjia, Zhaoquanhe and other towns and towns in Dongguo and Yangquan Town in Panshan County (Figure 3). The natural landforms include the following types: gravel sandy alluvial fan in Panjin region, flat depression, low wetland, low flat land, mud flats, sandbar, river, and flood plain (Table 1). The low flat land, low wetland, and flat depression are agricultural landforms, others are natural landforms. The flat land refers to the easily surface area with high topography, where the altitude is more than $4.5 \mathrm{~m}$; the low land level is $2.5 \sim 4.5 \mathrm{~m}$; the low wetland area is $1.5 \sim 2.5 \mathrm{~m}$. Tidal flats include tidal zone, intertidal zone, and subtidal zone. The tidal tidal currents are clear, the tidal trenches are everywhere. 
Table 1. Types of landform in Panjin region.

\begin{tabular}{lll}
\hline Main landforms & Types of landform & Characteristic \\
\hline \multirow{3}{*}{ Reef alluvial plain } & Beachfront & Slow bank slope, high beach surface, soil \\
& Tidal creek & Sticky Deep groove in the beach \\
& Tuozi & $1.5 \sim 2 \mathrm{~m}$ above sea level, beachfront highlands \\
& Floodplain & Water, uneven \\
Estuary alluvial plain & Hexinzhou & Silted into several highlands, over $2 \mathrm{~m}$ \\
& Gangzi & Bar highlands \\
& Sand dunes and sand & Along the banks of the sand highlands \\
\hline
\end{tabular}

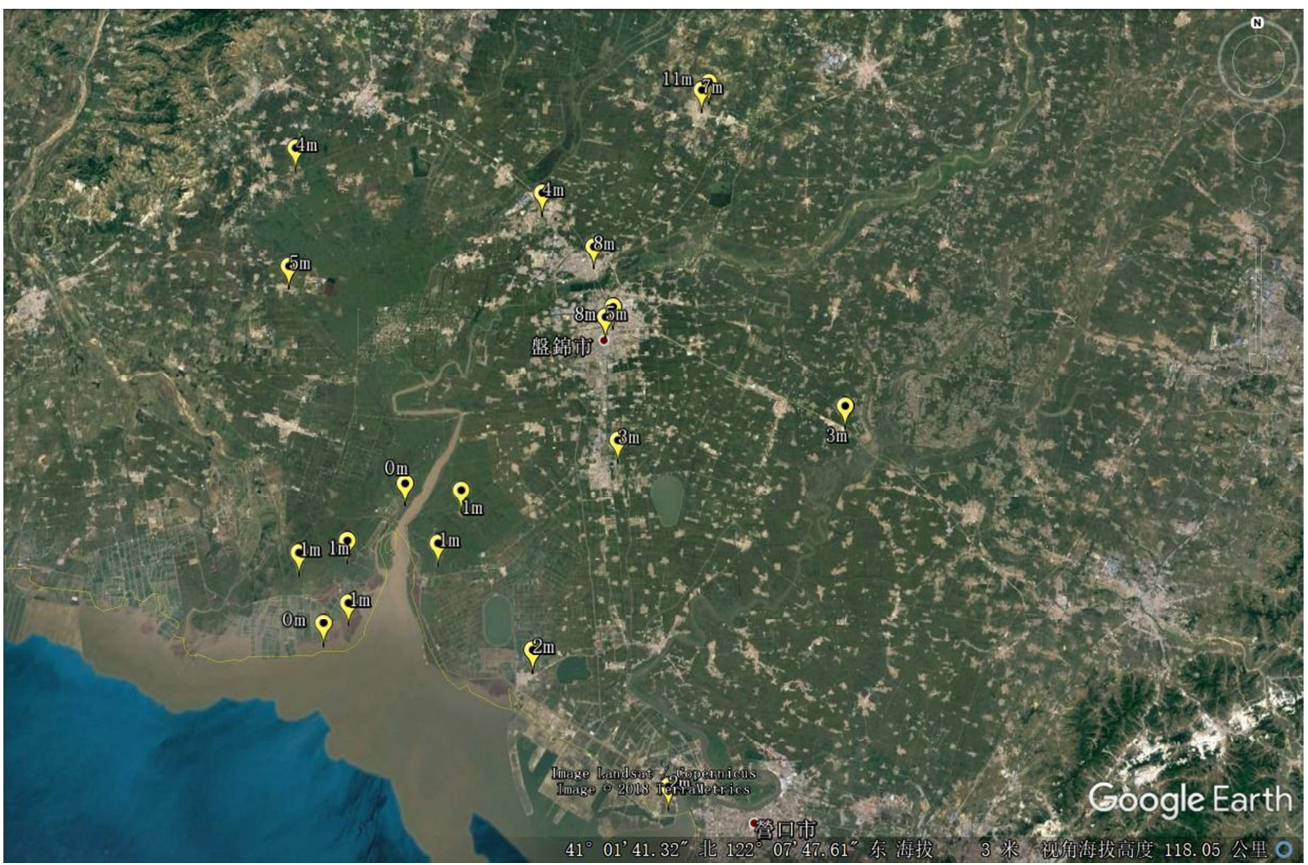

Figure 3. Topography and landforms.

\subsubsection{Soil}

The soil in Panjin region is divided into five soil classes and 10 subclasses. (Table 2).

The aeolian sandy soil are mainly located in the northwest and northeast. There are aeolian sandy soil in Gaosheng town, Xinzhen town and Xibin town in Panshan County. The total area is about $725 \mathrm{hm}^{2}$, which accounts for $0.3 \%$ of the total land area. Sand dunes have a smoother appearance and become undulating. It also contains a lot of meadow soil, with a total area of $67,986 \mathrm{hm}^{2}$, accounts for about $27.4 \%$ of the total land area. It is mainly formed on shallow banks along rivers, low-lying areas and alluvial plains. Saline soil, as long as the topsoil (depth within $0 \sim 5 \mathrm{~cm}$ ) measured more than $1 \%$ salt content belongs to saline soil. The main areas where saline soil is distributed are the western part in Panjin area and the southwest coast. The total area is $56,826 \mathrm{hm}^{2}$, accounting for about $22.9 \%$ of the total land area in Panjin. Marsh soil in the reed marsh area in the southwest position in Panjin and in low-lying areas of the plain, the total area of marsh soil is $28,612 \mathrm{hm}^{2}$, accounting for $11.5 \%$ of the total land area. According to the formation process, it is divided into two sub-categories: meadow bog soil and saline marsh soil. The main planting soil in Panjin is paddy soil, which has a large area in Panjin and is distributed in many places. Paddy soil occupies about $40 \%$ of land area in Panjin [11].

Table 2. Distribution of soil in Panjin region.

\begin{tabular}{|c|c|c|c|}
\hline Types of soil & Accounting for the soil area & Subclasses & Status f Growing vegetation \\
\hline The aeolian sandy soil & 0.3 & Fixed sandy soil & Corn, sorghum, soybeans and other crops \\
\hline Sand dunes & 27.4 & $\begin{array}{l}\text { Carbonate meadow Soil } \\
\text { Salinized meadow soil }\end{array}$ & $\begin{array}{l}\text { Growing reeds, thatch and other meadow } \\
\text { plants }\end{array}$ \\
\hline Saline soil & 22.9 & $\begin{array}{l}\text { Waterfront saline soil } \\
\text { Meadow saline soil } \\
\text { Swamp salt soil }\end{array}$ & $\begin{array}{l}\text { Salt-tolerant plants or semi-half-tolerant } \\
\text { plants such as soda and reeds }\end{array}$ \\
\hline Marsh soil & 11.5 & $\begin{array}{l}\text { Meadow swamp soil Salinized } \\
\text { swamp soil }\end{array}$ & Reeds, cattails \\
\hline Paddy soil & 37.7 & Submerged paddy SoilSalty paddy soil & Rice \\
\hline
\end{tabular}




\subsubsection{Vegetation}

Vegetation is an important component of landscape and is directly perceived as one of the most important visual features of landscape. Plants are affected by climate, soil, and topography, which in turn affect the environment. In landscape classification, vegetation is one of the most important indicators of landscape.[12]The soil in Panjin contains high concentrations of salt, and non-specific plants are difficult to survive. Therefore, the plant structure in this area is single, with fewer species of wood and more herbaceous plants with salt tolerance.

\section{(i) Species and Community of Herbaceous Vegetation}

There are more than 100 kinds of herbs, mainly salt-enduring plants, semi-half-enduring plants, freshwater mire plants. Large areas of wetland plants such as Phragmites australis, Typha, Suaeda salsa, Calamagrostis pseudophragmites, etc. are distributed. The economical plant reed and cattail biomass are large and the dominant population is large (Table 3).

Phragmites australis: Phragmites australis grows in low-humidity or shallow water, and its habitat requires areas with strong soil fertility, long-term wetlands and relatively high moisture content, such as swamps and rivers. These areas often have associated plants, such as Bolboschoenus strobilinus. Its plants are tall, with well-developed rhizomes, white powder under the joints, and straight stems. In Panjin region, there has a good reed field - the Liaobin reed field, where the reeds can grow into thick and strong stems. The stalk height is about $2 \mathrm{~m}$, and the yield per unit area is high. Although the area of Zhao quanhe open field is large, the yield is low, and the plant height of the reed is about 1 to $2 \mathrm{~m}$. It can be seen from Table 3 that the reed community is the main plant community type in Panjin area, with reed meadows and reed marshes. The reed marsh community is the most widely distributed and the largest in Panjin wetland. The groundwater level is usually $0.5 \sim 1.0 \mathrm{~m}$ or more, and the surface water will be accumulated year-round. Seasonal water will be formed under drought conditions. Generally, the water depth is $20 \sim 40$ $\mathrm{cm}$, and the soil salinity is generally below $0.48 \%$. The height of reeds is kept at $2 \sim 3 \mathrm{~m}$, and the coverage rate can usually reach more than $90 \%$. The reed meadow is distributed on the periphery of the reed marshes, and is slightly higher, with no stagnant water and seasonal water, the reed height is slightly lower, and the reed growth is sparser than that of the marshe.

Suaeda salsa: Suaeda salsa has extremely high requirements for habitats, such as a humid and salty environment, and a soil with more moisture. But because there is a lot of water in its leaves, it can accept transient droughts. Suaeda salsa in Panjin is also known as Suaeda heteroptera. It is 30 to $50 \mathrm{~cm}$ in height and is almost red throughout the entire growing season. There are tidal phenomena in the coastal beaches. Suaeda salsa changes according to the soil salinity. When the salt concentration is reduced, the amount will decrease, and other plants will appear one after another. There will be a single community of Suaeda salsa and the plant will be dominated by reeds and other plants. Suaeda heteroptera abundance community is mainly located in the low-lying areas on both sides of the tidal creek, and is mainly affected by the tide water. Intermittent distribution along the coast, with high salt content in the soil, the proportion is usually $0.7 \%$ to $1.5 \%$, so that the probability of survival of other plants is very small, only to retain some salt and alkali-resistant plant communities, Suaeda heteroptera is one of the pioneer plant communities.

Typha: It is a warm and wet habitat with plenty of sunshine. Therefore, it is preferred to cultivate in sunny areas and shallow waters. Born in ponds, damp, etc. Its plant height is about $2 \mathrm{~m}$ and above, often accompanied by reeds. Its main habitat is in reed fields and paddy fields, and is cut into slices. Perennial aquatic or marsh herb, water depth in rice fields is about $50 \mathrm{~cm}$. Cattail communities are distributed around basins and ditches. The water depth is about $50 \sim 60 \mathrm{~cm}$. In the community, there are P. typha and T. typha, the higher P. typha has two layers of growth. The Typha przewalskii with strong advantages is located in the upper layer, the plant height is $2.0 \sim 2.5 \mathrm{~m}$, and the coverage is $60 \% \sim 80 \%$ is the dominant species, followed by Typha davidiana, with a plant height of about 1 to $1.4 \mathrm{~m}$, about $80 \%$ coverage. There are aquatic plants such as Myriophyllum verticillatum growing in the community, Sagittaria natans. In addition, Typha przewalskii and Typha davidiana can also become independent communities.

Calamagrostis pseudophragmites: In the areas with flat terrain and good moisture, such as flat topography, farmland, etc., the soil of Calamagrostis species is mild to moderate salinization. It is a meadow building species.

\section{(ii) Species and Community of Woody Vegetation}

The woody vegetation mainly includes Robinia pseudoacacia plantations, hybrid poplar plantations, Populus pseudo-simonii and plantation of Populus simonii. The main species are Robinia pseudoacacia, Lespedeza davurica, Ostryopsis davidiana, Vitex negundo var. heterophylla, Ziziphus jujuba var. spinosa, and P. simonii $\times$ P. nigra., $P . \times$ canadensis cv. Sacrau, $P$. $\times$ beijingensis, P. pseudo-simonii, $P$. simonii, Salix cinerea, S. mongolica and Tamarix chinensis.

Table 3. Types of the main community.

\begin{tabular}{lll}
\hline Types of vegetation & Height/cm & Cover/\% \\
\hline Reed marsh community & $200 \sim 300$ & $80 \sim 90$ \\
Reed meadow community & $150 \sim 250$ & $40 \sim 60$ \\
Salix sophorae community & $30 \sim 50$ & $60 \sim 70$ \\
Cattail community & $200 \sim 250$ & $60 \sim 80$ \\
Reed and saline suaeda community & $150 \sim 250$ & $60 \sim 80$ \\
Reed and cattail community & $200 \sim 250$ & $70 \sim 80$ \\
\hline
\end{tabular}

\subsubsection{Water}

\section{(i) River}

There are 21 rivers in Panjin area, and the total river area is $3,750 \mathrm{~km}^{2}$. Among them, there are 4 large rivers with a total area of over $5,000 \mathrm{~km}^{2}$, it is the Liao River, the Daliao River, the Daling River, and the Raoyang River; The river area is within the range of $1,000 \sim 5,000 \mathrm{~km}^{2}$, which is a medium-sized river and has a Xisha River. Small rivers with a 
catchment area of less than $1,000 \mathrm{~km}^{2}$ have a total of 16 , they are the Panjin River, the Yue yazi River, the Shazi River, the Xiaoliu River, the Old Raoyang River, the Dayang River, the Fengtun River, the Nan pigang River, the Wailiao River, the Xinkai River, the Taiping River, the Yitong River, the Zhang jiagou, Chaogou, the Dong yazi River, and the Xi yazi River. The Liao River and the Daliao River are connected by the Xinkai River and the Wailiao River.

The river slope in panjin region is small, the average of $1 / 10,000$, the rivers are gentle. The longest river length is between 5 and $116 \mathrm{~km}$. The Liao River, the Daliao River and the Daling River have entered Liaodong Bay. Other crisscrossed rivers, many river are some river tributaries, such as the Xiaoliu River, the Nan pigang River and the Taiping River, are tributaries of the Liao River. The river section of the Liao River in Panjin was originally called the Shuang taizi River. It was a tidal creek, because of the flood later, new river channels were formed. The alluvial plain on the banks of the Liao River, with a flat topography. The river bank consists of weight loam, not resistant to rain, and the river forms are meandering. The quicksand is easily deposited in the lower reaches to form an alluvial plain. The river floodplain has semi-salt-tolerant reeds, cattails and other aquatic plants.

\section{(ii) Sea}

It is located in the northern part of Liaodong Bay and belongs to the shallow sea area in Panjin region. It is the coastal plain of the estuary and the silt of the river and the sea, there are many underwater sandbanks offshore, such as Men tougang, Lugang, Huang shagang and Hei gangtou. The total length of the shoreline is $57.5 \mathrm{~km}$. Sea ice is a major feature in Panjin Sea. The total area of tidal flats in Panjin is $3.55 \mathrm{hm}^{2}$, of which there are $23,700 \mathrm{hm}^{2}$ in coastal tidal flats and 11,800 $\mathrm{hm}^{2}$ in underwater sandbars. There are two major tidal flats: the Panshan County Beach and the Dawa County Beach. The area of the beach is relatively flat, and the beach ratio above the $2 \mathrm{~m}$ elevation is reduced by $1 / 10,000 \sim 1 / 30,000$. There are a lot of salt-tolerant plants like Suaeda salsa.

\subsubsection{Animals}

The main elements of animal landscapeare are birds, crabs, badgers and harbor seals in Panjin region. The habitat of Wetland Reserve in Panjin region is complex and the rivers are vertical and horizontal, and the species diversity is obvious. The wild ornamental animal resources are rare and diverse. It has a good habitat and a specific climate in Panjin Wetland, which is the main reason for the rich biodiversity in the region. There are 236 species of birds, 119 species of waterfowl and nearly 1 million birds. Red-crowned Cranes and Oriental White Pelicans come here to rest every year, with the former being up to 806 , accounting for about $45 \%$ of the world's wild animals, the latter has more than 1,000. Here is the world's cherished bird, Larus saundersi breeding here, and is also the southernmost limit for the breeding of red-crowned cranes. There are many crabs and cockroaches, and there are thousands of Phoca Linnaeus.

\subsection{Screening Regional Natural Landscape Elements}

\subsubsection{Objective Evaluation Standard of Regional Natural Landscape}

Regional natural landscapes are words derived from geographical landscapes. On the basis of regional landscape connotations, the author believes that regional natural landscapes are the constituent elements of natural landscapes and the natural growth of landscape types in the region's land, which can reflect an area's obvious regional characteristics. Whether it is called the geographical landscape of the area, it is considered five factors: first is time depth, whether the natural landscape elements and landscape types have been extended for a longer period of time. A universal century is used as a node, then this longer time should exceed the node. The second horizontal span can also be said to be the distribution area, whether its distribution is wide and the area is large, then whether it grows into a piece or interweaves into a net, last, whether it is unique and can be identified, and whether $\mathrm{V}$ is stable. Based on the natural objective conditions in Panjin region and the previous research, this paper defines the objective criteria of regional natural landscape elements and landscape types, namely time depth (over one hundred years), distribution area, continuity, uniqueness, and stability. (Table 4).

Table 4. Assessment criteria for geographical components of natural landscape.

\begin{tabular}{llllr}
\hline Types & $\begin{array}{l}\text { Formation more than a } \\
\text { hundred years }\end{array}$ & Acreage of distribution & \multicolumn{2}{c}{ Continuityof landscape } \\
\hline Geomorph ology & Yes & Widely distributed & Yes & Yes \\
Vegetation & Yes & Widely distributed & Yes & Yes \\
Water & Yes & Widely distributed & Yes & Yes \\
Meteoro logical & Yes & Widely distributed & Yes & Yes \\
Animal & Yes & A large amount & & Yes \\
Soil & Yes & Widely distributed & & Yes \\
\hline
\end{tabular}

\subsubsection{Regional Natural Landscape Elements}

It is a marshland in 5,000 years ago in Panjin region. The rivers are vertical and horizontal, woody plants can grow on the ground. On the banks of rivers, reeds and other wet-tolerant plants grow. The alkaline land grows with Suaeda salsa. [13] The elements of the natural landscape are more than 100 years old in terms of time.

Comparing the data in table 5 with the standards in table 4, the topographic features of natural landscape elements in Panjin region are landforms, soil, vegetation, water and biology, which can reflect the unique geographical features of natural landscape in Panjin region. 
Table 5. Objective assessment for geographical components of natural landscape.

\begin{tabular}{lllll}
\hline Types & $\begin{array}{l}\text { Formation more than a } \\
\text { hundred years }\end{array}$ & Acreage of distribution & Continuity of landscape & $\begin{array}{l}\text { Individualism of } \\
\text { landscape }\end{array}$ \\
\hline Geomorphology & Yes & Widely distributed & Yes & Yes \\
Vegetation & Yes & Widely distributed & Yes & Yes \\
Water & Yes & Widely distributed & Yes & Yes \\
Meteorological & Yes & Small distributiondistributed & No & Yes \\
Animal & Yes & A large amount & & Yes \\
Soil & Yes & Widely distributed & Yes & \\
\hline
\end{tabular}

\subsubsection{Characteristics of Regional Components}

Characteristics of Regional components in Panjin region are by a wide and flat terrain, vertical and horizontal rivers, and tidal creeks. The plants are relatively single, there are few woody plants, and there are many salt-tolerant wet plants. Large areas of 'Red Beach', vast reed marshes, reed meadows, and red and green dynamic zonal shoal landscapes have a distinct color season and are better than Red Beach, making Panjin the most iconic geographical symbol. The endless reeds and reeds in Suaeda Beach form an open and flat living space, creating a diverse ecological environment for birds and crabs. The landscape structure of the three large-scale groups has also become the most symbolic geographical symbol in Panjin region.

\section{Conclusion}

The elements of geographical landscape are screened out: Vegetation is the dominant factor; landforms and soil are the basic elements; water is the influence factor; birds and river crabs are the ecological elements.

Characteristics of Regional components in Panjin region are by a wide and flat terrain, vertical and horizontal rivers, and tidal creeks. The plants are relatively single, there are few woody plants, and there are many salt-tolerant wet plants. Large areas of 'Red Beach', vast reed marshes, reed meadows, and red and green dynamic zonal shoal landscapes have a distinct color season. It creates a diverse ecological environment for birds and crabs. Large-scale groups have also become the most symbolic geographical symbol in Panjin region.

\section{References}

[1] Zhu Jianning, The landscape garden culture that exhibits the characteristics of regional natural landscapes, 11rd ed., Beijing, Chinese Landscape Architecture, 2011, pp. 1-4.
[2] Lin Jing, Wang Xiangrong, Regional Characteristics and Landscape Forms, 6rd ed., Beijing, Chinese Landscape Architecture, 2005, pp. 16-24.

[3] Zhu Jianning, Based on self, according to local conditions to create regional garden landscape, vol. 55. Beijing, Landscape Architecture, 2004, pp. 52-55.

[4] Tiancheng Liu, Shizhu Lu, Plan and design of landscapes as a part of construction of beautiful village, 5rd ed., vol. 18. Changsha, Agricultural Science \& Technology, 2017, pp. 940-945.

[5] Gábor Mezősi, The physical geography of hungary, Berlin, Springer International Publishing, 2017, pp. 189-193.

[6] V. Tomaselli G. Veronico S. Sciandrello P. Blonda, How does the selection of landscape classification schemes affect the spatial pattern of natural landscapes? An assessment on a coastal wetland site in southern Italy, 15rd ed., vol. 188. Environmental Monitoring and Assessment, 2016, pp. 356-362.

[7] Colten Craig E, Landscape and place in the gegraphical review, 1rd ed., vol. 10. Geographical Review, 2010, pp. 1-5.

[8] Backhaus G., Murungi J, Symbolic landscapes, Berlin, springer netherlands, 2009, pp. 380-388.

[9] Wilson Samantha, Geographical experience and the question of landscape, 2rd ed., vol. 39. Brno Studies in English, 2013, pp. $37-53$

[10] Xiao Duning, Hu Yuanman, Li Xiuzhen et al, Research on landscape ecology of the Bohai Sea delta wetland. Beijing, Science and Technology Press, 1998, pp. 80-86.

[11] Local Records Office of the Panjin Municipal People's Government, Panji City History, Anshan, Fangzhi Press. 1998, pp. 156-166.

[12] Qian Yuguo, Zhou Weiqi, Li Weifeng, Han Lijian, Urban multi-hierarchical landscape classification methods based on types and factors, 15rd ed., vol. 35. Beijing, Chinese Journal of Ecology, 2015, pp. 54-58.

[13] Yang Chunfeng, Yang Hongqi, Liaoning Regional Culture Review, Shenyang, Liaoning People's Publishing House, 2014, pp. 34-37. 